\title{
Enfoques teóricos, lengua, literatura y docente
}

\author{
Rita \\ Dromundo Amores \\ UPN CEPE-UNAM
}

A través de los años quienes se dedican a la educación, ya sea en la docencia, la investigación o la planeación, han buscado la fórmula mágica que favorezca un mejor aprendizaje. La enseñanza de la lengua y la literatura no son la excepción. El camino recorrido merece ser revisado para comprender el proceso.

Reflexionemos sobre cómo las variaciones en la didáctica derivan de modificaciones tanto en las teorías de la especial idad, como en las corrientes pedagógicas y psicológicas que las sustentan. Analizaremos al gunos de los cambios más relevantes en la enseñanza de la lengua y la literatura y haremos énfasis sobre el papel que se pide desempeñar al docente, a la luz de dichas teorías y la transformación que se requiere para modificar los usos y costumbres impuestos por las teorías previas, finalmente comentaremos hacia dónde se encauzan las tendencias actual es y el tipo de maestro que demandan.

Antes de comenzar la revisión esimportantemencionar que el ingreso de una nueva corriente teórica, no implica la cancelación de la anterior, pues los enfoques posteriores han retomado conceptos previos y han hecho, a su vez, aportaciones, lo que implica una suma y no necesariamente una sustitución.

Empecemos por considerar a la Retórica. Uno pensaría que no tiene sentido remontarse tanto, sin embargo, en ella residen las bases del enfoque actual, que retomó gran parte de las propuestas generadas varios siglos antes de Cristo, en la antigua Grecia:

\begin{tabular}{|ll|}
\hline \multicolumn{1}{|c|}{ Retórica Clásica $^{1}$} \\
\hline Objetivos: & $\begin{array}{l}\text { Emplear los recursos más pertinentes } \\
\text { para el objetivo. } \\
\text { Planear una comunicación a partir de } \\
\text { una finalidad. }\end{array}$ \\
\hline
\end{tabular}




\section{Retórica Clásica \\ (continuación)}

\begin{tabular}{|c|c|}
\hline Objetivos: & $\begin{array}{l}\text { Mejorar la expresión a partir dela imitación. } \\
\text { Razonamiento persuasivo y ordenado de la verdad. }\end{array}$ \\
\hline Contenidos: & $\begin{array}{l}\text { Retórica, como teoría y práctica de la el ocuencia } \\
\text { hablada o escrita. } \\
\text { Observación y práctica. }\end{array}$ \\
\hline $\begin{array}{l}\text { Habilidades } \\
\text { a desarrollar: }\end{array}$ & $\begin{array}{l}\text { Encontrar y precisar el tema. } \\
\text { Organizar las partes integrantes. } \\
\text { Elegir las palabras y sus adornos. } \\
\text { Memorización. } \\
\text { Emitir el discurso. } \\
\text { Técnicas para expresar y ejercitar el pensamiento. } \\
\text { Hacer discursos eficaces y convencer. } \\
\text { Desarrollar la escritura creativa. }\end{array}$ \\
\hline Corpus: & Textos clásicos. \\
\hline $\begin{array}{l}\text { Aplicación } \\
\text { didáctica: }\end{array}$ & $\begin{array}{l}\text { Diálogo reflexivo. } \\
\text { Elaboración de discursos. } \\
\text { Comentario. } \\
\text { Imitación de modelos. }\end{array}$ \\
\hline Aportación: & $\begin{array}{l}\text { Define las reglas que rigen toda composi ción o discurso, } \\
\text { para influir en los pensamientos o sentimi entos de las per- } \\
\text { sonas. Esto es la conciencia de una finalidad comunicativa } \\
\text { para provocar al guna acción o reacción en el receptor y la } \\
\text { selección de los recursos más pertinentes para ello, con esto } \\
\text { conforma el sustento de la normativa, así como de la prag- } \\
\text { mática y el enfoque comunicativo actuales. }\end{array}$ \\
\hline $\begin{array}{l}\text { Papel del } \\
\text { docente: }\end{array}$ & $\begin{array}{l}\text { Propiciar la reflexión del al umno, a partir de preguntas, fa- } \\
\text { vorecer el uso conciente del lenguaje y adecuación de éste a } \\
\text { una finali idad: convencer. }\end{array}$ \\
\hline
\end{tabular}

Como podemos apreciar, varios de estos elementos están presentes en los nuevos enfoques, desgraciadamente fueron reemplazados por teorías posteriores, o bien limitadosa actos mecánicos, hasta quese retomaron recientemente. Más tarde surge la llamada: 


\section{Gramática tradicional²}

Tipo de

gramática:

Normativa, Aristotelismo.

Concepto

clave:

Palabra.

Traducir o copiar con exactitud.

Imitar a los clásicos.

Centro

Partes de la oración.

de análisis:

Ortografía, léxico y morfología.
2 Para los esquemas de lengua se tomó como punto de partida a Cuenca, modificado por Lomas Cómo enseñar a hacer cosas con las palabras. $v$ II, p.78 y por Cassany Enseñar lengua, p. 305. Los agregados y modificaciones son propias.

\begin{tabular}{|ll|}
\hline Conceptos: & $\begin{array}{l}\text { Correcto/ incorrecto. } \\
\text { Partes de la oración. } \\
\text { Oración simpley compuesta. }\end{array}$ \\
\hline $\begin{array}{l}\text { Aplicación } \\
\text { didáctica: }\end{array}$ & $\begin{array}{l}\text { Gramática normativa. } \\
\text { Gramática para traducción. }\end{array}$ \\
\hline & $\begin{array}{l}\text { Primera descripción de la lengua. } \\
\text { Análisis de la norma. } \\
\text { Gramáticas, diccionarios y traducciones. } \\
\text { Gramática de Nebrija 1492. } \\
\text { Humbol dt. Siglo xvill Teoría general del lenguaje } \\
\text { y visión de mundo que se retomarán más tarde. } \\
\text { El (la) profesor(a) promuevela memorización de conceptos, la } \\
\text { identificación de elementosy elaboración de oraciones, fuera } \\
\text { de contexto. Considera que el alumno sólo puede estar en lo co- } \\
\text { rrecto o equivocado, dependiendo del mayor o menor apego a } \\
\text { lanorma establecida por la gramática o por el (la) maestro(a). }\end{array}$ \\
\hline
\end{tabular}

Se tiende a menospreciar a esta gramática y a citarla como sinónimo de incorrecto y obsoleto, sin embargo, cada vez que al udimos al sistema de la lengua (gramática y normativa), estamos empleando los recursos aportados por ella.

Más tarde, como definir a los componentes de la lengua no bastaba, surge la: 


\section{Lingüística estructural}

Tipode Descriptiva.

gramática: Inductiva.

Concepto Signo

clave: Constituyente

$\begin{array}{ll}\text { Objetivos: } & \text { Adquirir los sonidos y conocer las } \\ & \text { Ortografía, léxico y morfología. }\end{array}$

Conductismo.

Centro de Funciones.

análisis: Paradigma.

Conceptos: $\quad$ Sincronía, lenguaje, lengua, habla, signo, sistema,

estructura, sintagma paradigma, nivel.

Aplicación Método audio-lingual.

didáctica Análisiscontrastivo.

\begin{tabular}{|c|c|}
\hline $\begin{array}{l}\text { Aportaciones } \\
\text { a la didáctica: }\end{array}$ & $\begin{array}{l}\text { Revolución en la lingüística con el Curso de lingüística } \\
\text { general de Saussure. } \\
\text { Descripción lingüística sistemática. } \\
\text { Atención a la lengua hablada. } \\
\text { Al considerar ala lengua como sistema designos, } \\
\text { querequieren ser interpretados, seabre la puerta ala Semiología. } \\
\text { El círculo de Praga agrega la relación entre habla y contexto. }\end{array}$ \\
\hline $\begin{array}{l}\text { Papel } \\
\text { del docente: }\end{array}$ & $\begin{array}{l}\text { Propicia el análisis de las funciones y las relaciones } \\
\text { intertextual es de los elementos del discurso. } \\
\text { Promueve el análisis y la identificación de los componentes } \\
\text { de oraciones elaboradas especial mente para la clase. } \\
\text { Al centrarse en las funciones, se consideran, por ejemplo, las } \\
\text { diferentes funciones que puede desempeñar un sustantivo, } \\
\text { como núcleo de objeto directo, sujeto... }\end{array}$ \\
\hline
\end{tabular}

Aunque ya no sólo se anal izan los componentes de la oración, sino también las funciones, que estos realizan y la manera como se relacionan entre sí; el límite para el análisis es el texto que se aborda, por lo que varios de los estructuralistas fundaron la semi ología, en la cuál se construye el sentido a partir delas relaciones que establecen los el ementos de un texto con otros signos ajenos a éste. 
Posteriormente se considera necesario estudiar la manera como se aprende la lengua materna, para aplicarlo a la enseñanza de ésta, de ahí surge la:

\begin{tabular}{|c|c|}
\hline \multicolumn{2}{|r|}{ Gramática generativa transformacional } \\
\hline $\begin{array}{l}\text { Tipo de } \\
\text { gramática: }\end{array}$ & $\begin{array}{l}\text { Descriptiva. } \\
\text { Predictiva. } \\
\text { Deductiva. } \\
\text { Explícita. }\end{array}$ \\
\hline $\begin{array}{l}\text { Conceptos } \\
\text { clave: }\end{array}$ & $\begin{array}{l}\text { Oración. } \\
\text { Competencia. }\end{array}$ \\
\hline Objetivos: & Adquirir la gramática. \\
\hline $\begin{array}{l}\text { Centro } \\
\text { de análisis: }\end{array}$ & $\begin{array}{l}\text { Categoría } \\
\text { Proceso } \\
\text { Innatismo }\end{array}$ \\
\hline Conceptos: & $\begin{array}{l}\text { Gramatical/ agramatical, competencia, actuación, oración, } \\
\text { transformaciones, reglas, principios. }\end{array}$ \\
\hline $\begin{array}{l}\text { Aplicación } \\
\text { didáctica: }\end{array}$ & $\begin{array}{l}\text { Enfoque cognitivo. } \\
\text { Análisis de errores e interlingua. }\end{array}$ \\
\hline $\begin{array}{l}\text { Aportaciones } \\
\text { a la didáctica: }\end{array}$ & $\begin{array}{l}\text { Noam Chomsky plantea la reflexión en torno a la gramáti- } \\
\text { ca universal, combinación entre capacidad innata (compe- } \\
\text { tencia) y posibilidad de múl ti ples combinaciones (trans- } \\
\text { formaciones). } \\
\text { Insistencia en el aspecto creativo del lenguaje, modelo cohe- } \\
\text { rentey completo de análisis. } \\
\text { Tratamiento innovador de los errores. }\end{array}$ \\
\hline $\begin{array}{l}\text { Papel } \\
\text { del docente: }\end{array}$ & $\begin{array}{l}\text { Asumir que la competencia no puede ser enseñada, pero sí } \\
\text { desarrollada, a partir del uso conciente de la lengua, en con- } \\
\text { textos vinculados con la real idad que tengan sentido para el } \\
\text { alumno. } \\
\text { Considera las aportaciones de la psicolingüística para pla- } \\
\text { near el aprendizaje. }\end{array}$ \\
\hline
\end{tabular}


Las aportaciones de esta gramática propiciaron un cambio determinante en la enseñanza de la lengua y el lenguaje, en general, pues ya no se buscaba solamente el conocimi ento de la manera en que está organizada la lengua, sino desarrollar la habilidad para la comunicación o competencia comunicativa, en contextos reales, no en oraciones aisladas.

Los estudios sobre lo que ocurre en la mente durante el aprendizaje dieron mayor claridad para replantear los planes y programas de estudio, tanto de la lengua materna como de las segundas lenguas.

Posteriormente se vio la necesidad de encauzar esa competencia al logro de la eficacia comunicativa, y se anal izan diversas subcompetencias que integran la competencia comunicativa, como la lingüística, sociolingüística, discursiva o textual, estratégica, literaria, semiológica, entre otras, con lo que se desarrolla la:

\section{Lingüística textual}

$\begin{array}{ll}\text { Tipo de } & \text { Descriptiva. } \\ \text { gramática: } & \text { Implícita. } \\ & \text { Inductiva. }\end{array}$

Conceptos Enfoque comunicativo

clave: $\quad$ Texto/ discurso

Adquirir competencia comunicativa.

Objetivos: Analizar y emplear los usos lingüísticos en un contexto y con una finalidad comunicativa.

Centro de análisis:

Proceso comunicativo.

Conceptos:

Pertinente/ no pertinente, competencia comunicativa, texto, coherencia, cohesión, progresión temática, registro, tipo de texto.

Aplicación didáctica:

Enfoque comunicativo Método funcional/ nocional Tipologías textuales 
Lingüística textual

(Continuación)

Aportaciones

a la didáctica:

Enfoque gl obalizador

Interdisciplinariedad

Lengua en uso

Atención al conjunto

El al umno deja su papel pasivo y se vuel ve partícipe en la planeación y desarrollo del curso.

El docente, a partir de la consideración de la diversidad de sus estudiantes en aspectos lingüísticos, culturales, comunicativos, de aprendizaje, de interacción social , busca favorecer que desarrollen su competencia comunicativa, esto es que conozcan el uso lingüístico y qué decir, a quién, y cómo decirlo, de manera apropiada en cualquier situación dada. Es decir, el uso lingüístico en un contexto social determinado; que adquieran las destrezas expresivas y comprensivas para un intercambio comunicativo entre las personas.

Para lograrlo emplea recursos y material es diversos, vinculados con el uso real de la lengua en circunstancias y contextos diversos. Promueve además la generación de la expresión creativa.

Consideremos ahora lo que ha ocurrido con relación a la enseñanza de la literatura.

En una primera etapa que va desde fines de la Edad Media al siglo XIX la finalidad es el aprendizaje del discurso oral y escrito y la adquisición de valores morales. Más tarde, aproximadamente desde el siglo XIX a mediados del XX surgió el Ilamado:

\begin{tabular}{|c|c|}
\hline & Historicismo ${ }^{3}$ \\
\hline Teorías: & $\begin{array}{l}\text { Romanticismo y positivismo. } \\
\text { Estilística. }\end{array}$ \\
\hline Objetivos: & $\begin{array}{l}\text { Conocimiento de obras y autores de la litera- } \\
\text { tura nacional para fortalecer la identidad. } \\
\text { Adquisición de val ores morales. }\end{array}$ \\
\hline
\end{tabular}

3 Para los esquemas de literatura nos basamos en A. Díaz Plaja retomada por Mendoza, La educación literaria, p. 56 y Cuadro 5 adaptado de Colomer, 1996 y de Lomas, 1997 en Lomas op. cit., p. 58) Los agregados y modificaciones son propias. 
Historicismo

(continuación)

Contenidos: Obras, autores y movimientos de la historia de la literatura.

Habilidades Memorización.

a desarrollar: Visión global.

Corpus: $\quad$ Textos épicos, líricos y dramáticos nacionales.

\begin{tabular}{|ll}
$\begin{array}{l}\text { Aplicación } \\
\text { didáctica: }\end{array}$ & $\begin{array}{l}\text { Lectura de fragmentos. } \\
\text { Cuadros sinópticos. } \\
\text { Antología de textos. } \\
\text { Cronología de autores y obras. }\end{array}$ \\
\hline Aportaciones: & $\begin{array}{l}\text { Recuperación de una literatura nacional. } \\
\text { Estudio de las figuras retóricas y los géneros literarios. }\end{array}$
\end{tabular}

José Abelardo Núñez, El lector americano. pp. 1-2.
Cito como ejemplo El lector americano, ${ }^{4}$ un libro de texto publicado en 1890, donde el autor dice a los niños que leerán el libro:

Después de haber recorrido los otros libros de El Lector Americano que preceden á éste, en los que se han ejercitado gradual mente en vencer las dificultades de la lectura, pueden decir ya que leen pasaderamente.

Pero, ¿podrían afirmar con igual convicción que leen correctamente...?

Me permito dudarlo.

Leer bien no es, amiguitos míos, cosa tan fácil como ustedes acaso creen.

Cuando se lee, no se trata solamente de repetir con claridad y correcta pronunciación las sílabas y palabras que se en- 
cuentran impresas en un libro, ni de marcar los acentos, la puntuación y los demás accidentes con que se señala la escritura.

Es necesario saber qué es lo que selee, comprenderlo, sentirlo, a fin de hacer que los demás que oyen leer lo comprendan y lo sientan igualmente.

I gual cosa sucede en la lectura, y por esto además de la puntuación, que sirve como en otro lugar hemos visto, para dar a cada frase el sentido que le corresponde, es necesario que el lector dé expresión ál o que lee por medio de la entonación de su voz.

Esta expresión, Ilamada también énfasis, se puede producir de dos maneras: por la fuerza dada a la voz al pronunciar las palabras, o por el tiempo empleado al hacer las pausas.

O sea que, según esta propuesta, para cubrir esta necesidad de comprender lo que se lee, para hacerlo bien, se requería intuición para adivinar el sentido del texto, a partir de saberes previos inexistentes y luego dar a conocer dicho sentido, a través de la entonación, para comunicar el mensaje. Los al umnos debían tratar de adivinar qué quería el maestro que dijeran.

En cuanto al historicismo, a pesar de los avances en la didáctica y en los estudios sobre el lenguaje y su función comunicativa, se siguen planeando los cursos de literatura como un listado de obras, ordenadas cronológicamente y se pierde de vista que un texto literario es un mensaje, con una final idad comunicativa específica, que emplea recursos determinados especial mente para propiciar acciones o reacciones en el lector. Al respecto dice Lomas:

“[...]se insiste en la idea de que enseñar literatura es [...] transmitir información común sobre los autores de nuestra historia literaria e intentar (casi siempre sin fortuna) el respeto y admiración hacia sus obras. Pese a la constatación del fracaso de este modo de entender la enseñanza de la literatura...el modelo di dáctico del historicismo sigue dominando al bachillerato y la universidad [... $]^{5}$

Por la necesidad de ver las especificidades del texto literario, que lo distinguen de otro tipo de textos, surge posteriormente el:
5 Carlos Lomas, op. cit., vol. I. p. 60 


\begin{tabular}{|c|c|}
\hline & Formalismo \\
\hline Teorías: & $\begin{array}{l}\text { Estilística poética. } \\
\text { Formalista. } \\
\text { Estructuralismo. }\end{array}$ \\
\hline Objetivos: & $\begin{array}{l}\text { Lectura y análisis científico del texto. } \\
\text { Considerar forma y contenido desde la obra. }\end{array}$ \\
\hline Contenidos: & Métodos de análisis, función poética. \\
\hline $\begin{array}{l}\text { Habilidad a } \\
\text { desarrollar: }\end{array}$ & $\begin{array}{l}\text { Análisis de la obra como particularidad. } \\
\text { Mecanicismo. }\end{array}$ \\
\hline Corpus: & Textos poéticos y narrativos de la literatura. \\
\hline $\begin{array}{l}\text { Aplicación } \\
\text { didáctica }\end{array}$ & Comentario de textos. \\
\hline Aportación: & $\begin{array}{l}\text { Mayor presencia de los textos literarios, unicidad de la obrali- } \\
\text { teraria, teoría del discurso, funciones y acciones en el relato, } \\
\text { actantes. }\end{array}$ \\
\hline $\begin{array}{l}\text { Papel del } \\
\text { docente: }\end{array}$ & $\begin{array}{l}\text { Propicia el análisis de las funciones y las relaciones } \\
\text { intertextuales de los elementos del discurso. } \\
\text { Favorece el estudio de las particularidades de una obra y el } \\
\text { comentario explicativo de los textos. } \\
\text { En un principio, en este enfoque no importa tanto el senti- } \\
\text { do, sino la forma y las funciones. }\end{array}$ \\
\hline
\end{tabular}

El análisis de los textos con las aportaciones de estas teorías permite la consideración de los recursos que se emplean para la elaboración de un texto literario y la manera como se relacionan para conformar unidades de sentido.

Muchos rechazan el análisis estructural, la mayoría de las veces por ignorancia, pues sus aportaciones para el conocimiento y examen del texto poético son imprescindibles para el estudio de la literatura.

La tendencia actual, como en la enseñanza de la lengua, está centrada en el al umno, más que en el docente, por lo que el enfoque predominante es la: 


\begin{tabular}{|c|c|}
\hline & Teoría de la recepción, ligada con las: \\
\hline Teorías & $\begin{array}{l}\text { Semiótica del texto. } \\
\text { Semiótica de la cultura. } \\
\text { Pragmática literaria. } \\
\text { Sociocrítica. } \\
\text { Psicología cognitiva. }\end{array}$ \\
\hline Objetivos: & $\begin{array}{l}\text { Adquisición de saberes y habilidades para la lectura } \\
\text { y el desarrollo de la competencia literaria. } \\
\text { Manejo libre y creativo de los textos. }\end{array}$ \\
\hline Contenidos: & $\begin{array}{l}\text { Estrategias para la lectura. } \\
\text { Técnicas para la escritura creativa. } \\
\text { Lectura y comentario de textos diversos. } \\
\text { Habilidad a desarrollar: gusto por la lectura. } \\
\text { Competencia lectora. }\end{array}$ \\
\hline Corpus: & $\begin{array}{l}\text { Textos variados de los autores sobresal ientes, clásicos, ac- } \\
\text { tuales, de literatura infantil ojuvenil, según el caso, revistas, } \\
\text { películas. }\end{array}$ \\
\hline $\begin{array}{l}\text { Aplicación } \\
\text { didáctica: }\end{array}$ & $\begin{array}{l}\text { Lectura, comentario de textos y modificación de éstos. } \\
\text { Taller de lectura. } \\
\text { Taller de escritura. }\end{array}$ \\
\hline $\begin{array}{l}\text { Papel del } \\
\text { docente: }\end{array}$ & $\begin{array}{l}\text { Favorecer el desarrollo de la competencia literaria de sus } \\
\text { alumnos, la cuál implica tanto conocimientos teóricos } \\
\text { como estratégicos y el desarrollo de diversas habilidades, } \\
\text { para la comprensión y la expresión, en un contexto social y } \\
\text { con una visión comunicativa, partiendo del principio de } \\
\text { que no existen comunicaciones neutras, sino que se preten- } \\
\text { de influir en el otro, propiciar una reacción en éste: }\end{array}$ \\
\hline
\end{tabular}

[...] la literatura es concebida desde un enfoque comunicativo como un tipo de discurso con una función social y comunicativa específica, la estética y lúdica, y la educación literaria tiene como finalidad esencial el desarrollo de la competencia literaria de los al umnos. Dicha competencia se basa en el desarrollo por parte de éstos de habilidades y estrategias comprensivas y expresivas que les permitan, a través de la formación de su propio intertexto, familiarizarse y disfrutar de las distintas manifestaciones literarias, adecuadas a su edad e intereses. ${ }^{6}$
6 José Abelardo Nuñez, Ellectoramericano, citado por Josefina Prado, Didáctica de la lengua y la literatura para educar en el siglo XXI, p. 337. 
7 Daniel Cassany, et.al. Enseñar lengua, pp. 488-489.
La competencia literaria es un componente más de la competencia comunicativa y debe sustentarseen el desarrollo de habilidades para la comprensión, la expresión y creatividad, para favorecer que el estudiante amplíe sus conocimientos lingüísticos y retóricos, su imaginación, creatividad y en suma, su cultura.

Aún más, como afirma Cassany la adquisición de una competencia literaria no está condicionada únicamente por la adquisición de conocimientos, sino también por el desarrollo de habilidades, de procesos cognitivos y actitudes que la favorecen, tal como se especifica en el siguiente cuadro: ${ }^{7}$

\begin{tabular}{|l|l|l|}
\hline Procedimientos & \multicolumn{1}{|c|}{ Conceptos } & \multicolumn{1}{|c|}{ Actitudes } \\
\hline Leer & Tradición literaria & Sensibilidad. \\
Escuchar & historia, autores, & Búsqueda del placer. \\
Hablar & obras, corrientes. & Criterio propio. \\
Escribir & Géneros y subgéneros: & Visión amplia: activa, \\
Interpretar & características, estructura, & productiva, partici pativa, \\
Analizar & convenciones. & etcétera. \\
Relacionar & Recursos estilísticos: & Capacidad de reflexión. \\
Valorar & técnicas, figuras. & \\
Comparar & & \\
\hline
\end{tabular}

Para lograr esto debe asignarse a la enseñanza de la lengua y la literatura el papel protagónico que le corresponde, al ser la lengua el mejor instrumento comunicativo que existe y la literatura la forma más elaborada y rica de discurso, dada su inmensa gama de posi bilidades expresivas.

Hoy la escuela debe responder a una serie de exigencias, tales como posibilitar que los alumnos adquieran instrumentos y técnicas de trabajo, aprendan de manera conciente, ejerciten el pensamiento crítico y comprendan un mundo caracterizado por la existencia de múltiples estímulos informativos, fundamental mente audiovisuales. Ante esta realidad, el papel del profesor-transmisor se ha vuel to obsoleto.

La actitud profesional de los docentes se habría de basar en los principios de adaptabilidad y flexibilidad ante 
un sistema social di námi co y cambiante y la construcción del conocimiento y las formas de saber contemporáneas. Estar abierta a todos los cambios que puedan generarse a partir del ejercicio de la libertad y la creatividad.

Deben tener en mente: Una concepción cognitiva del aprendizaje que tenga en cuenta que la construcción activa del conocimiento lingüístico por parte de las personas es consecuencia de una actividad mental que se produce en situaciones de intercambio comunicativo y de interacción social. ${ }^{8}$

El maestro más que el ser que sabe todo debe convertirse en un buen conductor y orientador del grupo que enseña a aprender. Con esto es muy probable que tengamos que modificar bastante nuestras actitudes; no dar órdenes o establecer normas rígidamente, sin explicaciones; tampoco debemos imponer nuestro criterio. Se debe ser flexible y tomar en cuenta las opiniones del grupo. El maestro debe ser un animador que ayuda al grupo a funcionar; estar abierto al cambio; retomar y anal izar las ideas que proporcionen los al umnos... ya que para lograr que nuestros alumnos sean creativos debemos empezar por ser creativos nosotros mismos. ${ }^{9}$

En suma, el (la) maestro (a) de lengua y literatura: debe ser un buen lector de literatura, investigador, si empre actualizado en teoría literaria y psicopedagogía, intercambiador de experiencias y conocimiento.

Ser además un propiciador del aprendizaje, transmisor de entusiasmo, que promueve la interacción en el grupo a través de estrategias variadas, considera la opinión y los intereses de sus estudiantes, favorece la construcción del conocimiento en sus alumnos, hace grato y cordial el aprendizajey el desarrollo de habilidades, favoreceel aprecio por la cultura y los val ores humanos así como el respeto a la diversidad.

En cuanto a la lengua, ayuda a concebir un mensaje, literario o no, como una visión particular de mundo, con una ideología, cierto grado de subjetividad y una finalidad comunicativa.

Sabe que el placer de la lectura es el resultante de la satisfacción de comprender e interpretar lo leído. Concibe a la formación literaria como capacitar para la interacción que supone el pacto de lectura que sugieren el texto y el autor.
8 L.S., Vygotsky, Pensamiento ylenguaje.

9 Cruz, Guadalupe y Omar Chanona, "Creatividad y aprendizaje", en Expresión y comunicación. p. 346. 
Como consecuencia de un docente así tendremos lectores que sean receptores activos, capaces de comprender, disfrutar y crear diversos ti pos de textos, que participen, cooperen e interactúen con el texto; concientes desu mundo y abiertos a diversas formas expresivas.

En suma, digamos, como conclusión: que la enseñanza que demos a nuestros alumnos no sea el ancla que los haga dependientes del maestro, sino alas que les permitan volar.

BIBLIOGRAFÍA

CASSANY, Daniel et. al. Enseñar lengua. 6a ed., Barcelona, Graó, 2000, (Serie Lengua, 117).

CRUZ, Guadalupe y ChANONA Omar, "Creatividad y aprendizaje" en Expresión y comunicación. México, SEP/ UNAM, 1984.

ECO, Humberto, "Sobre al gunas funciones de la literatura", en Sobre literatura. España. Océano/ Requer Editorial, 2002.

DROMUNDO A. Rita, “¿Qué vio el Quijote en la literatura que nuestros alumnos no ven y qué tiene que ver en ello el docente?" en Didáctica XXI. Revista de Ia Asociación de Profesores de Lengua y Literatura, núm. 3. México, agosto, 2000.

LOMAS, Carlos, Cómo enseñar a hacer cosas con las palabras. V. I. Teoría y práctica de la educación lingüística. Barcelona, Paidós, 1999. (Papeles de Pedagogía, 38).

- Cómo enseñar a hacer cosas con las palabras. V. II. Teoría y práctica de la educación lingüística. Barcelona, Paidós, 1999. (Papeles de Pedagogía, 39).

MendOZA FILLOLA, Antonio. La educación literaria. Bases para la formación de la competencia literaria. Málaga, España, Ediciones Aljibe, 2004. (Temas de Lengua y Literatura).

NúÑEZ, J osé Abelardo, El lector americano. Nuevo curso gradual de lecturas. Compuesto para el uso de escuelas hispanoamericanas. Libro Tercero. Nueva edición corregida y reformada en 1890. Nueva Cork/ Leipzig, D. Appleton y Cía/ F. A. Brockhaus. 
PRAdo ARAGonÉs, J osefina, Didáctica de la lengua y la literatura para educar en el siglo XXI. Madrid, La MuraIla, 2004. (Colec. Aula Abierta)

SELMES, Ian, "Los material es para aprender a aprender", en La mejora de las habilidades para el estudio. BarceIona, Ediciones Paidós, 1988. (Temas de Educación, 11) Tusón, J esús, El lujo del lenguaje. Barcelona. Ediciones Paidós, 1989. (Paidós comunicación, 36)

VIGOTSKI, L. S., La imaginación y el arte en la infancia. México, Fontamara, 1996.

_, Pensamiento y lenguaje, Buenos Aires, La Pléyade, 1977. 
